\title{
Development of a vocational and pedagogic position reflection of a doctor as part of continuing medical education program
}

\author{
Andrei Anatoljevich Bogatyrev ${ }^{1 *}$, Nina Pavlovna Vanchakova ${ }^{2}$, Anna Pavlovna \\ Chernyavskaya $^{2}$, Natalia Valerjevna Krasilnikova ${ }^{2}$, Elizaveta Aleksandrovna Vatskel $^{2}$, and \\ Anna Artemjevna Babina ${ }^{2}$ \\ ${ }^{1}$ Moscow Pedagogical State University, Institute of International Education, 119991, Moscow, Russia \\ ${ }^{2}$ Pavlov First Saint Petersburg State Medical University, Chair of Pedagogy and Psychology, \\ Postgraduate Education Faculty, 1197022, Saint Petersburg, Russia
}

\begin{abstract}
The article considers vocational and pedagogic position reflection as an important component of medical vocational continuing education of doctors. According to the general hypothesis of the study, a special program for training vocational and pedagogic position reflection can contribute positively to medical caregivers' vocational performance in treating patients, who experience troubles with medical compliance and adaptation to the disease. The key methods of the study include a literature survey and theoretical elaboration of the concept of the vocational and pedagogic position of a doctor reflection, meanwhile, the empirical research is based on formative pilot experiment, preceded and followed by testing medical learners' personal reflexivity readinesses (by using Karpov's questionnaire). The medical caregiver's 'reflective ability' (Bogin) was considered as a source of doctors' professionalization. Reflexivity was regarded as a key component of doctors' preparedness to show empathy and to provide proper pedagogic support for hemodialysis patients, receiving audio-therapy. The results of the study show significant positive dynamics in learners' cognitive sphere and critical thinking development, a high level of performance in role-played solving educational training healthcare cases, meanwhile personal reflexivity measurements have shown no statistically significant differences after training (according to Student's t-test). The latter experimentation result testifies the personal nature of the reflexivity feature.
\end{abstract}

\section{Introduction}

The article is dedicated to the development of axiological, cognitive, and communicative aspects of the vocational and pedagogic position reflection of a doctor within the frame of the modern medical humanities and communicative paradigm. The subject of the study is considered based on the case of audio-therapeutic support of hemodialysis patients. Audiotherapy is non-medicament support based on a specially composed musical playlist

* Corresponding author aa.bogatyrev@,mpgu.edu 
aimed at improving a psychological state of a patient and tolerance towards exhausting medical procedures (for example hemodialysis sessions). The need for extension of physician's professional competencies is driven by the contemporary bio-psycho-social paradigm of healthcare, that pays attention not only to somatic but also to social and psychological aspects of human life. The performance of the psychological and pedagogic patient support requires doctors to possess not only a stable complex of knowledges and skills (including 'hard-skills' and 'soft-skills'), but also to implement a conscious vocational position associated with the development of reflection and self-reflection of one's vocational behavior in interaction with patients. The article considers vocational and pedagogic position reflection as an important component of medical vocational continuing education of doctors. According to the general hypothesis of the study, a special program for training vocational and pedagogic position reflection can contribute positively to medical caregivers' vocational performance in treating patients, who experience troubles with medical compliance and adaptation to the disease.

\section{Methods of the study and the participants}

A conceptual analysis of the notion of the vocational and pedagogic position reflection of a doctor (based on literature survey); the conceptual analysis of the notion of the audio therapy support; the situational analysis of the hemodialysis patients' states and needs; formative pilot experiment, preceded and followed by testing medical learners' personal reflexivity readinesses, based on using the questionnaire of reflexivity by A.V. Karpov; educational case method; statistical analysis of the data. The participants of the empirical study were continuous medical education trainees.

\section{Literature review}

The concept of the vocational position of a physician in the literature is addressed in the following way. According to V.K. Solondaev, the vocational position of a physician is a specific phenomenon that arises within doctor's professional activity, and implies certain actions of a specialist towards various areas of his vocational activity: its scientific basis, regulatory and organizational foundations, and socio-ethical aspects (in particular considering communication to patients and their next of kin) [1]. V.A. Chulkova et al. consider physician's professional position to be the result of vocational self-determination and a factor that regulates professional behavior through norms and values that transfer into internal meanings. That is vocational position determines the ways of self-realization of a specialist [2]. The analysis of vocational activities of a doctor shows that basically, medical students have 'clinical orientation' (the motivation to master 'hard skills', to accomplish certain vocational activities, interest in it and so on) [3,4, etc] This medical calling presupposes motivation and values aimed at performing medical care. At the same time, pedagogic reflection vocational physician's position still receive insufficient attention in specialized literature.

Thus, pedagogic position in contemporary research is seen as "means of basic values realization of a person's relationship with the others, the unity of consciousness and activity [5]. The analysis of the research aimed at studying pedagogic position $[4,6,7]$ leads to the conclusion that this concept is mostly regarded in an axiological way, as a kind of particular "vision", "comprehension of the teacher in the profession", comprehension of attitudes towards the profession (and special vocational activities), its essence, principles, and other actors of vocational relations. At the same time pedagogic position is mostly considered within the frame of some educational model, not the healthcare services one. Various types 
of pedagogic positions have been specified and studied: the partnership one (A. Chernyavskaya) [7], the dialogue one (I.N. Koloskova) [8], the person-oriented one (V.P. Bederhanova [9]) etc.

Analysis of European scientific sources (articles, materials of congresses and seminars, national recommendations) has shown that the publications cover some selected aspects and manifestations of the pedagogic position of a doctor, however, in a somewhat unsystematic way and rather indirectly than directly. Issues of medical ethics and deontology [10] as well as the formation of patients' compliance and adherence to treatment $[11,12]$ have been considered. At the same time in the survey of European research articles, no stable special terminology has been elicited of the kind that in any way fully and accurately corresponds to the concept of our present research.

The definition of the vocational pedagogical position of a doctor was provided by E.A. Vatskel and N.V. Krasilnikova. It comprises the system of the physician's relationship to the pedagogical aspects of his/her vocational activity, which means the awareness of the importance of pedagogical interaction with patients, their kin; the intention, the willingness, and attitudes to implement pedagogical interaction with patients, as well as the presence of a special theoretical basis. The pedagogical position is expressed in conscious effective pedagogical activities based on the acquired practical skills and abilities. In fact, the professional pedagogical position of a physician can be is formulated as a kind of an inner statement "I am not only a doctor but also an educator who provides pedagogical interaction with patients and their kin." [13]. In other words, by advancing the concept of a vocational and pedagogic position reflection of a doctor, we appeal to the idea of 'humanitarization' and humanization of the medical profession in the age of high technologies.

The vocational and pedagogical position of a doctor is an integral personal characteristic of a specialist, associated with the awareness of the importance of pedagogic aspects of doctor's professional activity, as well as with the attitude towards the effective implementation of psychological and pedagogic interpersonal interaction with the patients. The pedagogic position is a key factor, contributing to the conscious and effective implementation of the psychological and pedagogical support of the patients. Its reflective component allows to reveal and to actualize the axiological and normative bases of professional activity and communication, to carry out the humanistic mission of a doctor.

The interest towards the pedagogic position of a physician is determined by the following conditions. Today the world experiences vigorous growth of chronic disease in the population. On the one side, it is partly caused by the increase in average life expectancy. On the other side, it is caused by the growing requirements for the quality of life. At the same time, significant importance belongs to various socio-economic and environmental factors that have a positive or negative impact on the quality of life, expressed in its material, communicative, biological, social and axiological aspects. A holistic approach to quality of life determines the need of contemporary society to develop and produce new forms and non-medicament means of influence in order to maintain, and improve patient's quality of life. The holistic approach also requires broadening of the competence range of a doctor not only in the sphere of treatment, rehabilitation and preventive activities but also in educative and psychological patient support as it is basis of compliance and the ability to determine the patient's life strategy in the face of chronic disease, in "the formation of motivation for a healthy lifestyle, and self-preserving behavior" [13].

One of the most common chronic diseases is chronic kidney disease, its terminal stage (the V stage) is associated with high mortality. End-stage chronic kidney disease (CKD stage V) requires expensive replacement therapy (hemodialysis, peritoneal dialysis) or kidney transplantation. Hemodialysis is the most common treatment for chronic renal 
disease (stage V). In general, it provides patients with a fairly high standard of living, but at the same time, this therapy is associated with disabilities, reduction of social ties, exhausting pain, and itching, which together affect powerfully the psychological state of patients, and often lead to mental, psychological and behavioral disorders.

Chronic kidney disease requires patients to change their habitual way of life, whereas the effectiveness of therapy largely depends on the patient and his/her behavior [14]. Compliance in patients' (adherence to treatment) can be promoted through psychological and educational interaction, and in particular - patient education (that has been shown in various previous research) [15 - 18].

The audio-therapeutic method of psychological and pedagogical support of hemodialysis patients responds to the need for non-medicamentous means of support and is aimed at correcting the patient's psychological state by involving one in the mode of reflective activity. This mode serves as a source of the formation of a motivational component, allowing to minimize destructive experiences and attitudes and to enhance medical compliance concerning the treatment sessions. The key conditions for achieving a positive audio therapy effect include the mature professional reflective pedagogical position of the physician, his/her preparedness and willingness to express empathy and pedagogical tact, as well as the patient's communicative readiness for self-support and self-development in the face of the disease.

The basis of the vocational and pedagogic position reflection of a doctor is a specialist's awareness of the pedagogical part of a doctor's profession, adopting a positive attitude towards pedagogical interaction with patients and their kin. It is associated with an orientation towards principles of humanity, ethics and deontoloogy [13]. Based on the tenets of pedagogy and focused on the person-centered approach to education [19], the pedagogic position of a doctor, practicing audio-therapy support implies empathy and a responsive approach to the patient's personality, "based on a deeper understanding of patients personality traits and living conditions". The designated approach to the pedagogical position of the doctor " means not the adjustment of education goals and its content to the person (the patient), ... but the adjustment of the forms and methods of pedagogical influence to patient's individual characteristics" in order to create conditions for the patient to take a reflective position, that can act as source of experience, "allowing to improve the entire mental and spiritual structure of the person" [20].

The patient-centered personal approach is especially relevant within audio therapy communication with hemodialysis patients. The comorbidity of the pathology in chronic renal disease case can sometimes cause the distortion of perception when interacting with the outside world (when self-communicating and interacting with "significant others"). Mastering the reflective position by the patient within audio-therapeutic communication is carried out in the course of training and self-training to read and understand certain situations, texts etc. The results of these training include learning (acquiring) reflection, as "the principle of independent action that can lead one ... to his/her own understanding, to his/her own decision, and to his/her own insights and discoveries" [20].

The pedagogical position of a physician within audio-therapeutic support requires mature pedagogical reflection, that is, the ability to independently appeal to self-awareness, to understand how the patient perceives one's own activity. The pedagogical position of a doctor also requires the ability to perform the reflective activity, to read and explain (interpret) certain musical compositions, to comprehend it widely, and to combine a reflective position and personal interpretation of the author's musical text associated with tailoring their own semantic construct. According to G.I. Bogin, a person who has acquired a pedagogical position is able to play various roles, that result in teaching the other people to perform reflective acts and reflection-based activity (within frame of audio-therapy 
support -fostering and developing patients' reflexivity. i.e. 'reflective ability' and reflection set towards the world and self in the context of disease and receiving treatment.).

High-quality audio therapy patient support is based on a well-developed professional and pedagogic position of the physician. One of its key components is a group of reflective readinesses, including a mature ability for self-cognition, axiological analysis and critical vocational self-assessment, as well as the expressed willingness and readiness for empathy, respect for patient's self-consciousness and self-reflections. It also includes doctor's readiness to manage one's own beliefs about one's vocational behavior as well as the readiness to facilitate patient's beliefs, perceptions and self-perceptions. The vocational psychological skills and pedagogic activity of a physician, who carries out audio-therapy support is treated as components of a pedagogical program of actions and interactions, performed in vocational communication with a patient. This program is targeted at facilitating the formation of the patient's readiness for self-controlled reflective activity, including the discovery and actualization of patient's personal meanings in the face of the disease.

The pedagogic position of a doctor in audio-therapeutic support of a patient is aimed at teaching the patient to grow aware of "his own mental processes, his own experiences as "the inner experience" [20] through a musical text. Educating within audio therapy support means awakening the reflection skills and activities, which leads to filling the patient's present existence with meanings and experiencing these meanings.

The patient's state is generally acknowledged to be better, when the patient experiences the feeling of being filled with meaningful experience and valuable social ties, and demonstrates awareness of the current situation and one's own mental processes. The caregiver's pedagogic activity within the framework of audio-therapeutic work does not lie in the field of "teaching understanding", because "teaching to understand" presupposes delivering some "ready-made understanding", excluding personalization the patient and the individual and subjective nature of his/her perception and reactions. The main task of pedagogic activity in audio-therapeutic patient support is to teach patient positive reflection and guide the patient's reflection in the cue, granting the highest attainable quality of life. The caregiver helps the patient in mastering reflective techniques as a way and method to achieve an understanding of one's situation as meaningful.

Audio-therapy support sets special requirements for the vocational and pedagogic position reflection of the doctor, due to the specificity of the its method, its emotiveness, and reflective components. Based on a mature professional pedagogical position, the physician / caregiver can achieve the necessary compliance of the patient, to determine the strategy of its development, to determine the approach to the patient as a person who finds oneself in a new and difficult life situation and needs the assistance that goes beyond the boundaries of strictly clinical competencies.

Reflection was understood by John Locke $(1632$ - 1704) as an observation to which human mind exposes the sources, means, processes, deeds, and results of its own activity [cf. 20; 21, 22 etc.]. The basis of any reflection is a reflective act, the direction of which can vary widely from focus on an object, phenomenon, process, action, condition, connection, goal (cognitive reflection) to focus on the sources, results, methods, and means of positing a reflective object (meta-cognitive reflection), as well as on the goals, objectives, conditions, motives and means of communication (meta-communicative reflection) that determine the goals, values and norms of life and activity (axiological reflection). Russian scientific tradition defines many other types and subtypes of reflection: the ordinary one, the ontological one, critical, the meta-linguistic one, the pedagogical one, the methodical one, the "reflection for reflection" one, the stop-reflection one and others $[21 ; 22,486]$. At the same time, pedagogical reflection itself is responsible for the balance of freedom and culture in a person [21]. 
Following Pierre Teilhard de Chardin, it should be noted reflection's fundamental connecting, humanizing and personalizing role, in which the subject knowing himself forms a "single whole, aware of his organization" [23]. The question of whether it is possible to teach a person to reflect and (as a result) understand remains one of the debatable issues in psychology and pedagogy. Nevertheless, vocational education makes it possible to form and develop the tools of reflection, its directedness, normativity, equipped with hermeneutic tools (terms and concepts), based on specific approaches and methods, the effectiveness of reflective acts in vocational contexts. By describing any specific techniques of reflection, we rely on the concept of reflection readiness (G.I. Bogin, [20] etc.). Speaking about the organic unity of reflective readinesses in the formation of the image of the situation of professional activity in the professional self-consciousness of a doctor, we can state one's vocational and pedagogic position reflection. In the second case, the term "reflection" appeals to holistic self-awareness, based on the completeness of the cycle of reflection, which returns a person to oneself as a person and the subject of vocational calling and vocational responsibilities. The pedagogic position reflection of the doctor is viewed as a component of vocational one under the condition of interpersonal communication with patients.

The development of a vocational and pedagogic position reflection of a doctor can be carried out in the form of advanced training, focused on the formation of special competencies in the field of psychological and pedagogical support of hemodialysis patients by means of audio therapy. The training under such a program, in addition to the formation of ideas about the specifics of psychological and pedagogical support, audiotherapy, etc. is focused on the development of doctors' ability for a vocational and pedagogic position reflection-based understanding of themselves and their roles in psychological and pedagogical support of the patient, their personal responsibility for showing empathy, pedagogical tact, for stimulating constructive reflection experience of patients.

\section{Results}

In the training course, the following pedagogical conditions were implemented. The training itself followed the basic module, dedicated to the foundations of pedagogic interaction. The specially developed final module included training focused on the application of audio-therapy methods. The learners were expected to practice the competencies acquired during the previous (theoretical) module of study. They had to trace their own professional and pedagogic position reflection of a doctor; as well as support the acquisition of the experience of reflective comprehension and provide assistance to the patient to get such kind of experience within a communicator-centered approach [22]. It was part of learners' vocational integration into the world standard of professionalism, based on such principles as "be present, focused and engaged with your patient" [24, 758$]$.

In the process of training doctors were offered special cases, and then asked to perform the analysis of it on their own, targeted at forming the axiological reflection component of doctor's professional (vocational and pedagogic) position. Role-played business games provided the learners (the physicians) with the opportunity to model the experience of pedagogic interaction with patients. The teacher proposed a certain situation (for example, "Informing the patient about a new medicine ", "Formation of motivation for adherence to a special diet"), which took place or could take place in real life, the students analyzed the problem, the given conditions and suggested individual ways of solving it, or solutions developed in small groups, the results were evaluated.

The training sessions were aimed at developing communicative competence, reflection, tolerance, empathy. These included special exercises for developing communicative 
competence and empathy, for example, "Attentive listening" [25]. There were group discussions - the participants shared their views on possible obstacles that can interfere with active listening and reflection; there were training games (for example, "Broken Phone"), followed by discussion, focused on the analysis of the specifics of the patients' models of the universe and the individual patterns of the perception of disease experience. Discussing such questions as: "Do you feel that you understand each other? Why?" (for the speaker); "How do you understand that your communication partner deeply understands you?", "How did this specified feeling affect you?" (for the listener) were aimed at triggering and showing learners' empathy and reflective skills in vocational medical context.

Modeling situations of audio-therapy and support of a patient, taking into account the dynamics of each patient's feelings and perceptions, unique worldview and individual experience made it possible to form and practice reflective skills in demand for audiotherapy. The use of the psycho-dramatic method allowed to form the experience of decentration, which also had a positive effect on the formation of reflectivity and empathy skills, essential in the vocational and pedagogic training of doctors.

Forty two doctors (18 women and 24 men, average age $42,08 \pm 10,02$, job tenure 19,52 $\pm 9,98)$ took part in the training according to the modular program. At the initial and final control stages of training, in addition to checking knowledges, skills and abilities, the levels of students' reflexivity were analyzed (by using the A.V. Karpov reflexivity questionnaire) [26]. According to the results of the final module, the number of doctors with a high level of reflection was (22 people) $52.3 \%$, an average of $47.7 \%$, (20 people), a low level of reflexivity among doctors was not recorded (0 people), which indicates a sufficiently developed reflective abilities and preparedness in the physicians.

Mean values of the reflexivity level of respondents at the initial stage of the course and at the final assessment (by the end of the training course) they were quite high. Comparison of mean values using Student's t test did not show statistically significant differences, that is, the level of students' reflexivity (as a personal quality) did not change significantly.

Table 1. Mean values for the level of reflexivity at the initial and final assessment

\begin{tabular}{|c|c|c|c|}
\hline Reflexivity level & initial assessment & final assessment & P \\
\hline Reflexivity indicator & $142,46 \pm 16,69$ & $142,8 \pm 17,11$ & 0,41 \\
\hline
\end{tabular}

At the same time, the analysis of the knowledge component of the vocational and pedagogic position reflection of the doctor (knowledge of the specifics of reflection and empathy, the individuality of the worldview, the doctor's full and deep awareness of the pedagogical aspects of one's professional activity, its goals, awareness of the process of working with the patient as a source of pedagogic goals and tasks, vision of the student in the patient, the analysis and reflection of one's own pedagogical style) revealed a significant increase. The skills assessment for solving situational problems, analyzing cases, role-playing vocational business games also revealed the high level of output of such skills formation.

\section{Discussion}

The formation of a pedagogical position reflection of the physician within the vocational development course allowed health practitioners to form a new complex of knowledge and skills in the field of vocational and pedagogic reflection and self-reflection. At the same time no statistically significant changes in levels of stable vocationally significant personal qualities such as levels of reflexivity were revealed. 
As can be seen in the data in the table, no statistically significant changes in the initial and final levels and reflexivity were recorded. Probably, this was due to the fact that reflectivity (i.e. reflective ability) is a vocationally significant personal quality that is partly genetically inherent and partly may demand a long-term development in the course of the professional and personal growth of each doctor. At the same time, it should be noted that the formation of the cognitive component of the vocational and pedagogic position reflection of the doctor took place - trainees' ideas about the essence of psychological and pedagogic support, the role of empathy and reflection in this process, awareness of the uniqueness of the patient's worldview and the perception the uniqueness of the experience of each person. The formation of vocational and pedagogic position reflection of the doctor within a postgraduate training course for physicians made it possible to form a complex of knowledges and skills in the field of vocational reflection and self-reflection of a doctor. However, it did not affect vehemently the personal characteristics of the trainees, such as personal levels of reflexivity.

\section{Conclusion}

The vocational and pedagogic position reflection of the doctor, along with the proper level of professional knowledge, "hard skills" and "soft skills", is a source of focus and effectiveness of medical practice. The vocational and pedagogic position reflection of the doctor includes a hierarchy of axiological determinants of vocational activity, providing for the optimal choice of goals, means, methods, risks and responsibility for achieving the result, active participation in medical treatment management, and rehabilitation. Medical caregiver' s 'reflective ability' can be considered as a source of doctors' professionalization, a source of doctors' preparedness to show empathy and to provide proper pedagogic support for hemodialysis patients, receiving audio-therapy. The results of the study show significant positive dynamics in learners' cognitive sphere, and critical thinking development, a high level of performance in role-played solving educational training healthcare cases, meanwhile personal reflexivity measurements have shown no statistically significant differences after training (according to Student's t-test). The latter experimentation result testifies the personal nature of reflexivity feature. It implies the importance of doctor's early vocationalisation in educational institutions, as well as the need for longitudinal study of doctor's reflexivity dynamics in the long-term vocational practices.

By means of vocational and pedagogic position reflection of the doctor communicative field of trustful dialogical communication is formed. This field of trustful dialogue allows to perform mutual communicative and reflective activities of the patient and the physician. It is aimed at patient's self-awareness, comprehension of existence obtained, at gaining new meanings and constructive self-understanding of the disease. The list of relevant components of the vocational position reflection of a doctor should include the formed pedagogic and meta-communicative (reflective) position of the doctor as vocational communicator, that provide a necessary condition for successful performing psychological and pedagogical support of patients.

The physician performing the role of the experienced interlocutor and the role of the "significant other" contributes to the patient's adaptation to new reality and acquisition of personal meanings under given conditions of disease and medical care. Effective reflective pedagogical activity within vocational context of audio-therapy in hemodialysis patient support requires a physician to rethink the axiological directedness and guidelines of therapeutic interpersonal interaction, a transfer of the vocational point of interest from focusing on a disease or a clinical case to healing as a holistic process that includes, in addition to clinical medical intervention, expedient emotional connection with patient, 
empathy and pedagogic components of communication. Solving the tasks of patients' support can be based on the development of a holistic vocational and pedagogic position reflection of the doctor, based on one's preparedness for reflection and meta-reflection.

\section{References}

1. V.K. Solondaev, The professional position of the doctor. in Personality and Being: Subjective Approach: Proceedings of Scientific. Conference, Institute of Psychology RAS, 15-16 October 2008, Moscow, Russia (2008)

2. V.A. Chulkova, V.A., E.V. Pestereva, E.V. Demin, M.V. Rogachev. Psychological aspects of interaction between a doctor and an oncological patient. Textbook, $\mathrm{SPb}$ : Research Institute of Oncology named after V.I. N.N. Petrova, 40 (2015)

3. Kuzmina, N.V. Methods of systemic pedagogical research (Moscow, Public education, 2008)

4. Markova, A.K. Psychology of professionalism (Moscow, International Humanitarian Foundation "Knowledge" 1996).

5. N.M. Borytko, O. M. Matskaylova. Formation of the subject position of the student in the humanitarian space of the lesson (Volgograd, Publishing house of VGIPKRO, 2002)

6. E.I. Isaev and V.I. Slobodchikov. Psychology of human education. Formation of subjectivity in educational processes. Textbook. (Publisher: Orthodox St. Tikhon University for the Humanities, 2014)

7. A.P. Chernyavskaya, Formation of the teacher's partner position: dis. ... Dr. ped. Sciences 2007, Yaroslavl. $450 \mathrm{p}$.

8. I.V. Koloskova, Formation of the dialogical position of the future teacher in the process of teaching pedagogical disciplines at the university, dis. Cand. ped. Sciences, $2011.204 \mathrm{p}$.

9. V.P. Bederkhanova, Formation of a personality-oriented position of the teacher, dis. ... Dr. ped. Sciences: Krasnodar, 2002. 413 p.

10. William T Branch Jr. Treating the whole patient: passing time-honored skills for building doctor - patient relationships on to generations of doctors, JME, 48. 67-74 (2014)

11. S. Dor Goold, M. Lipkin Jr. The Doctor, Patient Relationship, JGIM14: 1, 26-33 (1999)

12. N. Kerse, S.Buetow, A.G. Mainous III, G. Young, G. Coster, B. Arroll PhysicianPatient Relationship and Medication Compliance: A Primary Care Investigation, The Ann. Fam. Med., 2:5, 455-461 (2004)

13. E.A. Vatskel, N.V. Krasilnikova Formation of the professional pedagogical position of doctors in the system of continuous medical education, Yaroslavl Pedagogical Bulletin. 2, 128-132 (2017)

14. N., Shangolian, H. Yousefi Supporting hemodialysis patients: a phenomenological study, Iran. J. Nurs midwifery. 20:5, 626-633 (2015)

15. K. Parvan, H. Hasankhani, A., Seyyedrasooli, S. M. Riahi, M. Ghorbani The effect of two educational methods on knowledge and adherence to treatment in hemodialysis patients: clinical trial, IJCS 4:1, 83-83 (2015) 
16. T. Barnett, T. Li Yoong, J. Pinikahana, T. Si-Yen Fluid compliance among patients having hemodialysis: can an education program make a difference? JAN 61:3, 300-306 (2008)

17. S. Baraz, S. Parvadah, E. Mohammadi, B. Broumand Dietary and fluid compliance: an educational intervention for patients having hemodialysis, JAN, 66:1, 60-68 (2010)

18. T. Golper Patient education: can it maximize the success of therapy? NDT, 16:7, 20-24 (2001)

19. I.P. Podlasy Pedagogy: 100 questions - 100 answers: textbook. manual for university students. (Moscow, Publishing house VLADOS-PRESS, 2006)

20. GI Bogin Gaining the ability to understand: An introduction to philological hermeneutics. (Tver: Tver. state univ. 2001).

21. A.A. Bogatyrev, Some pedagogical innovations of the innovative course, Foundations of Religious Cultures and Secular Ethics. TvSU Bulletin. Series: Pedagogy and Psychology 2, 122-132. (2012)

22. A.A. Bogatyrev, Testing psychological dispositions and the professional qualities of future 'ORKSE' teachers. Moscow, Scientific journal Modern problems of science and education (ISSN 2070-7428), 2, 486. (2014) URL:

https://elibrary.ru/download/elibrary_21471595_28121621.pdf; URL: https://scienceeducation.ru/pdf/2014/2/486.pdf (04/04/2020)

23. Teilhard de Chardin P. The world of philosophy: A book for reading. (Moscow, Part II. S. 76-80, 1991)

24. N.V. Krasilnikova, P. Vaucher, N.P. Vanchakova, A.A. Bogatyrev, E.A. Vatskel, A.A. Baraboshina, Inverted Classroom as Innovative International Educational Technology in Teaching Doctors in Global Challenges Era, Proceedings of the "New Silk Road: Business Cooperation and Prospective of Economic Development" (NSRBCPED), November 7-8, 2019, Saint-Petersburg - Prague, Russia - Czech Republic (2019) URL: https://www.atlantis-press.com/proceedings/nsrbcped-19/125937799

25. Increasing empathy: Manual. Empathy training. 60 (2013)

26. A. V. Karpov, Reflexivity as a psychological atribute and methods of its diagnostics, Psychological journal. 24, 5, 45-57 (2003) 